\title{
Territórios da Boa Nova: os espaços da festa e os limites da palavra
}

GUILHERME AMARAL LUZ*

Resumo: Neste artigo, observamos como os espaços nos quais davam-se as festas religiosas quinhentistas no Brasil eram constituídos como festivos. Ao mesmo tempo, visamos perceber as diferentes formas de festas comportadas em cada espaço como limites estabelecidos para a proclamação do testemunho cristão.

Abstract: In this article, we observe how the spaces in which the sixteenth century religious festivities occured in Brazil were made festive. Besides, we aim to perceive the different forms of festivities held in each space as stablished limits to the proclamation of the Christian testimony.

Palavras-chave: Festa religiosa. Jesuítas. Discurso religioso.

Key words: Religious celebration. Jesuits. Religious discourse.

A partir, da leitura de cartas de missionários jesuítas do primeiro século da colonização e da narrativa epistolar de Fernão

O texto que segue é um excerto do segundo capítulo de nossa dissertação de mestrado. Nele, discutimos as transformações que as festas religiosas do Brasil quinhentista processavam no espaço, para configurá-lo como festivo, instaurando uma temporalidade própria, na qual o testemunho cristão poderia ser proclamado. Corresponde, com leves modificações, ao trecho que vai da página 58 a 66 , fazendo parte do segundo item do Capítulo II: "Com fome de cera: os sentidos da festa para a religiosidade cristã no Brasil quinhentista." Ver: LUZ, Guilherme Amaral. As festas e os seus papéis: as representações e dramatizações alegóricas jesuíticas no interior das festas religiosas do Brásil quinhentista. Campinas: Universidade Estadual de Campinas, 1999. Dissertação de mestrado orientada pelo professor Dr. Paulo C. Miceli e julgada pela banca examinadora composta pelos professores Dr. Alcir Pécora e Dr. Leandro Karnal, no dia 25 de março de 1999.

* Mestre em História Social pela Universidade Estadual de Campinas (UNICAMP) e aluno de doutorado da mesma. 
Cardim, percebemos a íntima relação entre a escolha dos espaços e a intervenção simbólica neles como fundante dos tipos de festa neles projetados. As correspondências jesuíticas visam prestar contas com as autoridades da Companhia de Jesus a respeito da festa como prática legítima e adequada aos projetos missionários. Por isto, local, momento, público participante, práticas e símbolos devem formar uma totalidade articulada que permita uma comunicação eficaz da "verdade" cristã, dando conta de afetar os participantes, ao mesmo tempo que sem ferir a ortodoxia. Os espaços da festa são, assim, entendidos como horizontes de sentido, cenários significativos, territórios não só físicos, mas também limites do discurso religioso.

Fosse em Portugal, no mar, nas colônias da África, da Ásia ou da América, a festa cumpria um papel importante para a vida religiosa durante o século XVI. Um estudo de Renata de Araújo sobre a cidade de Lisboa e seus "espetáculos" na época dos descobrimentos revela a espetacularidade permeando uma ampla parcela das práticas sociais em Lisboa. Segundo a autora, as festas, as procissões, enfim, todas as formas de espetáculo eram ocasiões para uma simbiose do sagrado e do profano, sendo que considera sagrado como simbolismo religioso e profano como necessidade de prazer. ${ }^{2}$ As festas ocupavam as ruas, as igrejas, os espaços públicos em geral, toda a cidade. Também Paulo Miceli, em seu $O$ ponto onde estamos, menciona a espetacularidade como fortemente presente na vida de Lisboa e destaca a procissão como principal espetáculo. As ocasiões para as procissões eram múltiplas: recebimentos de monarcas, pedidos a Deus para que afastasse epide-

2 Ver: ARAÚJO, Renata de. Lisboa - a cidade e o espetáculo na época dos descobrimentos. Lisboa: Livros Horizonte, 1990. p. 31-32. A distinção, contudo, entre sagrado e profano proposta por Renata de Araújo é questionável. O sagrado não se caracteriza por um conjunto de símbolos estabelecidos a priori em contextos isolados das práticas religiosas de um certo universo místico. Antes, como aponta Mircea Eliade, preferimos entender o sagrado como um fenômeno identificável no momento em que se apresenta como uma experiência religiosa (ELIADE, Mircea. Origens: história e sentido na religião. Lisboa: Edições 70, 1989, p. 9-13), o que, de maneira alguma, exclui o elemento do prazer. Tal elemento pode ser caracterizado como sagrado, desde que faça parte de algo que se apresenta como uma suspensão do tempo profano, visando uma reinstauração do tempo essencial das origens. Assim, a "festa" não é uma mistura ou simbiose do sagrado e do profano, mas, é uma forma legítima de manifestação do sagrado. A associação entre profano e prazer é um juízo de valor contemporâneo e ocidental daquele que considera as práticas religiosas da igreja, hoje, algo monótono e sem atrativos. 
mias, para que chovesse, para se rezar para um bom parto da rainha, entre outras. ${ }^{3}$ No mar, também percebemos a relevância das comemorações religiosas. Diz Miceli que: "Todas as datas do calendário litúrgico eram comemoradas pelos embarcados". ${ }^{4}$ Algumas de tais comemorações a bordo são comentadas por Fernão Cardim e envolviam, além de procissões, sermões, ladainhas, misereres, fogos, disparos de peças de artilharia, entre outras atividades. ${ }^{5}$ Em colônias asiáticas como o Japão, também temos informação a respeito da importância das comemorações festivas de caráter religioso, promovidas ou incentivadas por missionários, incluindo representações teatrais no seu interior. Em The church militant and iberian expansion, C. R. Boxer diz: "No Japão, como em outros lugares, os missionários jesuítas encorajavam os conversos a encenarem representações teatrais de natureza religiosa, particularmente nos dias de festas principais, como Natal, Páscoa e Dia de Reis (6 de janeiro) [...]. Eram representadas cenas bem elaboradas, acompanhadas tanto por música européia quanto japonesa." Também em Boxer, observa-se a força das celebrações e a importância das procissões, das representações e da música para a vida religiosa e para o esforço missionário das diversas ordens religiosas com as quais trabalha no "Novo Mundo".

Havendo uma cruz, alguns padres, orações, música, algumas relíquias de santos e representações de tipos religiosos, todo lugar era passível de abrigar festas, de modo que não havia um espaço específico como um templo, uma praça pública ou um palco ao qual a festa deveria ser adaptada, mas, ao contrário, era a festa que tornava os espaços festivos, fossem eles em Portugal, nas naus ou em terras longínquas. Não havia lugares específicos para a festa, todo o mundo era palco para o espetáculo da cristianização. Nas cartas dos primeiros jesuítas do Brasil percebemos uma quantidade variada de espaços que se mostram como privilegiados para o acontecimento de festas: os portos, margens de rios, ruas de aldeias e vilas, interiores de colégios e igrejas, entre outros. O espaço da festa fornecia como que um horizonte de significados possíveis e sua descrição nas cartas é sempre significativa, mostrando-o como

MICELI, Paulo. O ponto onde estamos - viagens e viajantes na história da expansão e da conquista. São Paulo: Scritta, 1994, p. 55-56.

Id., p. 167-173.

CARDIM, Fernão. Informação da missão do P. Cristóvão Gouveia às partes do Brasil - Anno de 83. In: Tratados da terra e gente do Brasil. São Paulo: Nacional, 1936. Introdução e notas de Batista Caetano, Capistrano de Abreu e Rodolfo Garcia, p. 173.

BOXER, C. R. The church militant and Iberian expansion - 1440-1770. London: The Johns Hopkins University Press, 1978, p. 58. 
o cenário das festas e dos espetáculos religiosos. Embora as festas constituíssem os espaços como festivos e não o contrário, os sentidos de cada festa relacionavam-se aos locais em que ocorriam as celebrações.

Na carta ânua de 1584, o Pe. José de Anchieta descreve uma celebração no dia da invenção da Santa Cruz, na qual o santo lenho e outras relíquias foram expostos na igreja e, em seguida, transladados pelos corredores do colégio da Bahia. Diz Anchieta que o corredor foi ricamente adornado, com toda a pompa e solenidade exigida pela situação, sendo expostos quadros, flores, tapetes, as relíquias de todos os santos e cofres elaborados. Apenas os padres, os irmãos e os noviços da Companhia de Jesus participavam da procissão, sendo que os primeiros traziam relíquias de santos, enquanto os outros empunhavam velas. Os padres estavam muito bem e ricamente vestidos e os noviços e irmãos vestiam sobrepelizes. A apenas alguns "fidalgos" foi concedida permissão para presenciar a celebração. Anchieta nos relata que tamanha foi a admiração desses senhores ao ver a festa que, diante da perfeição e do fervoroso ambiente devoto, emocionaram-se muito, levando-os a espalhar louvores à Companhia de Jesus pela cidade e a fazerem doações para o Colégio.' Tais celebrações, ocorridas no interior dos colégios e destinadas a um público reduzido, evidenciavam a afirmação da Companhia de Jesus e da sua hierarquia como proclamadora do testemunho cristão através de uma linguagem legitimada, qual seja, a dos rituais solenes e devotos. Tal legitimação também era evidente nas festividades em que membros da Companhia de Jesus eram promovidos ou faziam votos em público. ${ }^{8}$

Em muitos aspectos, as festas realizadas no interior dos colégios se diferenciavam daquelas realizadas, por exemplo, no porto, na praia ou nos arredores de uma aldeia ou vila, quando se festejava a chegada de um visitante. Muitas vezes, os rios tornavam-se locais para encenações de batalhas à maneira indígena, fazendo parte de recebimentos. Também, em pequenos bosques, ocorriam recebimentos, incluindo, como nos informa Cardim, danças, músi-

Carta ânua da Província do Brasil, de 1583, Do Provincial P. José de Anchieta ao Geral P. Cláudio Acquaviva. Bahia, $1^{2}$ de janeiro de 1584. In: ANCHIETA, José de. Cartas - correspondência ativa e passiva. São Paulo: Loyola, 1984. Pesquisa, introdução e notas de Hélio Abranches Viotti, p. 351.

8 Ver: Carta ânua de 1584, ou Breve narração das coisas atinentes aos colégios e residências, existentes nesta Província do Brasil - Bahia, 27 de dezembro de 1584. In: id, p. 383 . 
ca e representações (o que muito impressionou o jesuíta, causando-lhe devoção, dado o contraste entre aquela "gente bárbara" naquela "terra estranha" e um sentimento positivo em relação à festa ${ }^{9}$.

Os recebimentos eram práticas festivas das mais comentadas nas cartas jesuíticas e podiam conter, entre outros elementos, música, jogos, representações e palavras de saudação e louvor. Habitualmente, o recebimento fazia parte de festas maiores e, do porto, partiam todos em procissão para a aldeia ou para a vila, onde o restante da festa haveria de ocorrer. Aos recebimentos comparecia todo o tipo de gente, membros do clero, leigos e indígenas, fossem eles homens, mulheres ou crianças. Em muitas descrições, realizadas por missionários, de recebimentos, percebe-se a utilização de elementos da saudação indígena, como é o caso do chamado ereiupe, traduzido pelos padres-línguas como vieste na forma interrogativa e que era entendido como a própria forma dos índios de receber seus visitantes. Seguia, normalmente, ao ereiupe a frase "Louvado seja o Senhor Jesus Cristo" dita em tupi. Em muitos casos eram preparados textos para serem proferidos em versos no momento da chegada do visitante e a "calorosa" recepção sempre é descrita nas cartas como um belo momento, digno de muito apreço. Menos reservadas, regradas e programadas do que as festas ocorridas nos colégios, quando poucos as presenciavam, as festas ao ar livre, fossem em vilas, aldeamentos ou em seus arredores, proporcionavam um grande número de inovações nas práticas e nas formas de pregar, celebrar e proclamar o testemunho cristão. As representações, os jogos "à maneira dos índios" e as pregações do "meirinho" são algumas de tais novidades.

Fosse nos portos, nas ruas de vilas e cidades, na praia, nas embarcações ou no interior de prédios, o espaço das festas era o meio natural no seu estado intocado - como os rios e bosques nos quais ocorriam recebimentos - ou levemente transformado pelas mãos do colonizador. A própria "cidade colonial", no século XVI, como nos lembra Sérgio Buarque de Holanda, "[...] não chega a contradizer o quadro da natureza, e sua silhueta confunde-se com a linha da paisagem." ${ }^{\prime 10}$ As aldeias jesuíticas, no Brasil quinhentista,

CARDIM, Fernão. Informação da missão do P. Cristóvão Gouveia às partes do Brasil - Anno de 83. In: Tratados da terra e gente do Brasil, p. 177.

HOLANDA, Sérgio Buarque de. Raízes do Brasil. Rio de Janeiro: José Olympio, 1936, p. 62. Também em outras obras, como em Caminhos e fronteiras, Sérgio Buarque de Holanda desenvolve a idéia de que o colonizador aproveitou o saber indígena e as 
também possuíam uma estrutura simples, principalmente se comparadas às aldeias do século posterior na região do Prata. Os colégios da Companhia de Jesus eram construídos aproveitando as condições geográficas do local a ser escolhido. Segundo Nóbrega, a natureza do local condicionava a construção de um colégio. ${ }^{.1} \mathrm{~A}$ arquitetura das igrejas destacava-se pela pobreza e sobriedade, não se impondo perante a natureza, ${ }^{12}$ ao mesmo tempo tão assustadora e edênica, ${ }^{13}$ que se apresentava aos olhos do colonizador. A preparação especial dos espaços para as festas se caracterizava pela transformação mínima da natureza. Muitas vezes, o espaço natural era transformado apenas no seu som pelo canto e música ou na sua fisionomia pela simples passagem e bailados da própria procissão com suas relíquias, velas e crucifixos.

Muitas vezes, dependendo das necessidades de cada festa, algumas construções simples eram erguidas para abrigar representações. Cardim nos informa que uma vez foi recebido o Padre Visitador Cristóvão Gouveia nos arredores da aldeia do Espírito Santo, quando se representou um "diálogo pastoril" em língua portuguesa, brasílica e castelhana debaixo de uma ramada. ${ }^{14} \mathrm{O}$ "palco" do "teatro" jesuítico no Brasil quinhentista era muito simples, era o próprio meio natural, levemente modificado, de modo que seu significado como cenário era mínimo, liberando um vastíssimo horizonte de significados para aquele que presenciava as cenas, confundindo-se com os próprios significados implícitos nas características da natureza brasílica para o recém chegado colonizador. Limites mais definidos de significados davam-se menos

condições naturais do meio para promover a colonização. Ver: HOLANDA, Sérgio Buarque de. Caminhos e fronteiras. 2. ed. Rio de Janeiro: José Olympio, 1975.

${ }^{11}$ Carta a Santo Inácio de Loiola. De S. Vicente, 25 de março de 1555. In: LEITE, Serafim. Novas cartas jesuíticas (de Nóbrega a Vieira). São Paulo: Nacional, 1940, p. 57.

12 Ver: CARVALHO, A. M. (org.). A forma e a imagem: arte e arquitetura jesuítica no Rio de Janeiro colonial. Rio de Janeiro: PUCRJ, s.d.

${ }_{13}$ As imagens associadas à natureza brasílica colonial foram trabalhadas, com grande força, por Sérgio Buarque de Holanda em Visão do paraíso e por Laura de Mello e Souza em $O$ diabo e a Terra de Santa Cruz. Enquanto o primeiro enfatiza o caráter edênico da natureza como fator que teria, inclusive, incentivado a colonização, Laura de Mello e Souza mostra que a visão edênica da natureza convivia, ao mesmo tempo, com uma visão detratora. A autora de O diabo e a Terra de Santa Cruz concorda que tenha predominado a visão edênica da natureza, mas retira-lhe a exclusividade. Ver: HOLANDA, Sérgio Buarque de. Visão do paraíso. In: Visão do paraíso, São Paulo: Brasiliense, 1992, p. 185-246. E, também, MELLO e SOUZA, Laura de. O novo mundo entre Deus e o diabo. In: O diabo e a terra de Santa Cruz. São Paulo: Cia das Letras, 1987, p. 21-85.

${ }^{14}$ CARDIM, Fernão. Informação da missão do P. Cristóvão Gouveia às partes do Brasil - Anno de 83. In: Tratados da terra e gente do Brasil. p. 183. 
pelo cenário estático que se montava do que pela combinação das práticas de representação, das pregações de caráter pedagógico e dos elementos artísticos de caráter performático que nele eram realizados.

Era comum, no cenário do "teatro" jesuítico, se encontrar o elemento da surpresa e do inesperado. A chuva era de tais elementos o mais ameaçador e, contra ela, tinham os jesuítas, na maioria das vezes, apenas a sua fé de que não seria vontade divina estragar uma festa devota. É neste sentido que se atribui a Anchieta, em suas biografias, santidade por ter "previsto", certa vez, que não iria chover até que se terminasse uma encenação, mesmo estando o céu muito carregado, ${ }^{15}$ mostrando a importância da espiritualidade para o controle da natureza e conseqüente sucesso das práticas missionárias, o que justifica a imagem que se constrói de Anchieta como "taumaturgo do Novo Mundo". Se, por um lado, contudo, a possibilidade de chuva colocava o sucesso de uma representação em xeque, por outro, o triunfo sobre a ameaça enquadrava-se no universo semântico da festa. A chuva e as outras adversidades do meio, no contexto da festa, podem assumir significados religiosos próprios, que se relacionam às dificuldades para a ação missionária. Vencer as adversidades naturais, utilizando os escassos recursos disponíveis para isso, constituía a purificação do meio físico e a reconciliação, mesmo numa temporalidade própria, do homem com a natureza edênica. A vitória contra os empecilhos naturais significava o sucesso da evangelização em meio a uma "ordem corrompida", dominada pelo pecado.

No Brasil quinhentista, era a própria prática da festa, do jogo, do espetáculo, da música e da dança que evidenciava o espaço como festivo. As decorações, salvo quando se tinha uma celebração solene e reservada a poucas pessoas nos colégios, eram simples e singelas. Normalmente eram flores, folhagens, ramadas e algumas relíquias exibidas no momento das procissões. Raramente algum ornamento de maior porte era construído. Contudo, em 1584 , a recém-criada Confraria das Onze Mil Virgens promove, na Bahia, uma festa em homenagem às mártires, incluindo uma representação que trazia, até mesmo, uma nau sobre rodas devidamente escondidas de modo que ninguém as podia ver. Segundo Anchieta, em sua ânua de 1584, dentro da nau, muito ornamenta-

\footnotetext{
5 Ver: VASCONCELOS, Simão de. Vida do venerável Padre José de Anchieta. Porto: Lello \& Irmão, 1953, p. 52-53. E, também, RODRIGUES, Pero. Vida do Padre José de Anchieta da Companhia de Jesus. In: VIOTTI, Hélio Abranches (org.). Primeiras biografias de José de Anchieta. São Paulo: Loyola, 1988, p. 79.
} 
da, representava-se o martírio de Santa Úrsula e suas companheiras. ${ }^{16}$ Tamanhas produções, contudo, eram exceções e, mesmo no caso citado, o que se fez foi aproveitar algo já existente, uma nau qualquer, para representar a embarcação das Onze Mil Virgens, não tendo sido construída muita coisa especificamente para a festa. ${ }^{17}$ Simples ou não, contudo, os elementos que marcam a configuração do espaço como festivo transformam o sentido do local em que a festa se dava. O porto, assim, tornava-se um local de recebimento; as ruas e corredores, locais das procissões; as ramagens, locais para uma representação ou diálogo; enfim, todos os espaços se apresentariam como sagrados, a partir dos quais seriam proclamadas mensagens religiosas reconhecidas como legítimas e verdadeiras. Os espaços, mais do que mera ambiência, constituíam cenários significativos, podendo assumir, para o participante da festa, amplas possibilidades de reconhecimento de sentidos, valores éticos, morais e religiosos.

No momento da festa todo espaço se torna sagrado, mas as parcelas do sagrado são distribuídas diferentemente. A distribuição dos sentidos conferidos aos espaços festivos não é aleatória. Um templo pode agregar formas que são impossíveis de se encontrar ao ar livre, nas ruas ou no meio natural, assim como não pode outras. As regras da distribuição simbólica do espaço são delineadas pelas fronteiras da ortodoxia e pelos horizontes da experiência missionária jesuítica. As primeiras alargam-se em direção ao Novo Mundo, trazendo suas instituições, rituais, templos e colégios. Os segundos deparam-se com uma natureza desconhecida a ser controlada, a ser compreendida. Na experiência evangelizadora, os missionários descobrem a potencialidade dos rios para a encena-

\footnotetext{
${ }^{16}$ Carta ânua de 1584, ou Breve narração das coisas atinentes aos colégios e residências, existentes nesta Província do Brasil - Bahia, 27 de dezembro de 1584. In: Cartas - correspondência ativa e passiva, São Paulo: Loyola, 1984. Pesquisa, introdução e notas de Hélio Abranches Viotti. p. 375-376. Santa Úrsula seria uma das onze mil virgens que tiveram seu martírio em Colônia no século V d.C., quando foram massacradas pelos Hunos em defesa da virgindade. No Brasil, foram trazidas algumas relíquias das mártires, chamadas "cabeças das Onze Mil Virgens" e as festas em celebração ao martírio das virgens era freqüente em todo o território colonial português na América. É preciso dizer que, havendo a possibilidade, adornos especiais eram elaborados para a celebração de uma festa. Um exemplo disto é o frontispício pintado, na Bahia, pelo Pe. Manuel Álvares para a ocasião das celebrações da Semana Santa, como nos informa António Blazquez em sua carta para Diego Laynes de 1 de setembro de 1561. Ver: LEITE, Serafim. Cartas dos primeiros jesuitas do Brasil. São Paulo: Nacional, 1954, v. 3, p. 411.
} 
ção de jogos navais, dos bosques para pregações, das ramadas como palco de representações, dos portos para recebimentos. Ao mesmo tempo que as fronteiras do cristianismo se alargam, seus horizontes são ampliados no contato com outros mundos, ganhando cores novas, novas formas e instaurando outras práticas. Antes, contudo, de ter sido uma ação conciliatória entre ortodoxia e meio, a ampliação dos horizontes cristãos foi uma necessidade de manter a natureza estranha e adversa sob o controle da fé. Somente em solo cristão, as sementes da evangelização poderiam crescer, gerando os frutos almejados. Assim, a experiência missionária não poderia transparecer, nas cartas, como estranhas à ortodoxia, mas, ao mesmo tempo, havia de oferecer caminhos para solucionar problemas práticos da situação específica encontrada na terra do Brasil.

\section{Referências bibliográficas}

ANCHIETA, José de. Cartas de Anchieta, correspondência ativa e passiva. São Paulo: Loyola, 1984. Introdução, tradução e notas de Hélio Abranches Viotti.

ARAÚJO, Renata de. Lisboa - a cidade e o espetáculo na época dos descobrimentos. Lisboa: Livros Horizonte, 1990.

BOXER, C. R.. The Church militant and Iberian expansion (1440-1770). London: The Jonh Hopkins University Press, 1978.

CARDIM, Fernão. Tratados da terra e gente do Brasil. 3. ed. São Paulo: Nacional, 1936.

CARVALHO, A. M. (org.). A forma e a imagem: arte e arquitetura jesuítica no Rio de Janeiro colonial. Rio de Janeiro: PUCRJ, s.d.

GADAMER, Hans-Georg. A atualidade do belo - a arte como jogo simbolo e festa. Rio de Janeiro: Tempo Brasileiro, 1985.

GADAMER, Hans-Georg. The relevance of the beautiful and other essays. Cambridge: Cambridge University Press, 1986. Translated by Nicholas Walker and edited by Robert Bernasconi.

HOLANDA, Sérgio Buarque. Raízes do Brasil. Rio de Janeiro: José Olympio, 1936.

HOLANDA, Sérgio Buarque. Caminhos e fronteiras. 2. ed. Rio de Janeiro: José Olympio, 1975.

HOLANDA, Sérgio Buarque. A visão do paraíso. São Paulo: Brasiliense, 1992.

LEITE, Serafim. Cartas dos primeiros jesuítas do Brasil. São Paulo: Nacional, 1954.

LUZ, Guilherme Amaral. As festas e seus papéis: as representações e dramatizações alegóricas no interior das festas religiosas do Brasil quinhentista. Campinas: Universidade Estadual de Campinas, 1999, dissertação de mestrado.

MELLO E SOUSA, Laura de. O diabo e a terra de Santa Cruz. São Paulo: Cia. das Letras, 1987.

MELLO E SOUSA, Laura de. Inferno atlântico. São Paulo: Cia. das Letras, 1994.

MICELI, Paulo. O ponto onde estamos. São Paulo: Scritta, 1994. 